\title{
THE INFECTIVITY OF CHORIO-ALLANTOIC MEMBRANE IN- FLUENZA VIRUS AND INCOMPLETE INFLUENZA VIRUS BY THE SIX-HOUR SOLUBLE ANTIGEN PRODUCTION TEST
}

\author{
By A. J. BEALE aNd N. B. FINTER* \\ Public Health Laboratory, Northampton
}

(With 4 Figures in the Text)

\section{INTRODUCTION}

The infectivity of an influenza virus preparation is conventionally measured by determining the dilution at which unit volumes of virus inoculated into fertile eggs by the allantoic route will produce haemagglutinins in the allantoic fluids of half of them after incubation for $72 \mathrm{hr}$. Such a test (the $72 \mathrm{hr}$. haemagglutinin formation test) is described under methods, and in this paper the term infectivity used without qualification will imply measurement in this way.

Other criteria can, however, be used as the basis for an infectivity test. Thus measurement can be made of the amounts of the soluble complement-fixing antigen present in the chorio-allantoic membranes of eggs $6 \mathrm{hr}$. after intraallantoic inoculation of virus dilutions. Such a test (the $6 \mathrm{hr}$. soluble antigen production test) has been used by Hoyle (1950) for rapid determination of the approximate amounts of infective virus in 'standard' allantoic fluid influenza virus, i.e. that harvested $18-24 \mathrm{hr}$. after inoculation of small amounts $\left(10^{3}-10^{4} \mathrm{ID}_{50}\right)$ of seed. The relative infectivities of two such preparations are the same when measured by this test and by the $72 \mathrm{hr}$. haemagglutinin test. Subsequently, the $6 \mathrm{hr}$. test was applied to extracts of chorio-allantoic membranes harvested $4 \frac{1}{2} \mathrm{hr}$. after inoculation of large amounts of standard virus. It was found that by this test the membranes were highly infective, and produced much more soluble antigen than the same numbers of $\mathrm{ID}_{50}$ of allantoic fluid standard virus (Beale, 1954). Thus the two infectivity tests gave discrepant results with the two different virus preparations.

In this paper further studies are presented on the infectivity by the $6 \mathrm{hr}$. soluble antigen production test of different influenza virus preparations. It is shown that by the $6 \mathrm{hr}$. test chorio-allantoic membranes harvested from 3 to at least $21 \mathrm{hr}$. after inoculation of a large amount of seed virus are all more infective than equivalent amounts (in terms of $\mathrm{ID}_{50}$ inoculated) of standard virus. A similar effect is also found with 'incomplete' virus obtained by serial passages of undiluted allantoic fluid (von Magnus, 1951).

\section{METHODS AND MATERIALS}

Virus. The D.S.P. strain of influenza A virus (Hoyle, 1948) was used throughout these studies. Fresh 'standard' virus was prepared for each experiment by in-

* Member of the External Staff of the Medical Research Council. 
oculating 12th-day fertile eggs with approximately $10^{4} \mathrm{ID}_{50}$ by the intra-allantoic route, and harvesting the allantoic fluid 18-24 hr. later.

Haemagglutinin titrations. A modification of the pattern test (Salk, 1944) was used. After a preliminary titration when necessary, the virus preparation was diluted directly in saline to within about four twofold steps of the end-point. Six twofold serial dilutions were then made in $0.4 \mathrm{ml}$. volumes of saline in roundbottomed tubes $\left(3 \times \frac{3}{8}\right.$ in.), and an equal volume of a fresh $0.4 \%$ guinea-pig red cell suspension was added. After shaking, the tubes were left at room temperature until the cells had completely settled. The haemagglutinin titre per $0.4 \mathrm{ml}$. was the reciprocal of the final virus dilution in the tube showing a standard degree of partial agglutination, or was interpolated from the dilutions in the two tubes showing more and less agglutination. Titres were expressed in logarithmic haemagglutinin (HA) units per $\mathrm{ml}$. They were adjusted to standardized values by reference to the mean titre obtained with a concentrated virus control preparation included in each set of titrations (Miller \& Stanley, 1944).

Infectivity titrations: the $72 \mathrm{hr}$. haemagglutinin formation test. Tenfold or fourfold dilutions of the preparation were made in $10 \%$ horse-serum saline containing 500 units of penicillin and $100 \mu \mathrm{g}$. streptomycin per $\mathrm{ml} .0 .5 \mathrm{ml}$. amounts of four consecutive dilutions were inoculated into groups of five 1lth-day eggs. After incubation for $72 \mathrm{hr}$. at $37^{\circ} \mathrm{C} ., 0.4 \mathrm{ml}$. of allantoic fluid was tested for the presence of haemagglutinins. The dilution of virus at which $50 \%$ of the eggs would be infected (one $\mathrm{ID}_{50}$ ) was calculated by the method of Reed and Muench (1938), and the titre was expressed in logarithmic $\mathrm{ID}_{50}$ per ml. If titrations could not be performed at once, the freshly harvested materials were diluted $1 / 10$ in normal horse serum, which had been previously heated at $56^{\circ} \mathrm{C}$. for $\frac{1}{2} \mathrm{hr}$., then sealed in Pyrex ampoules, frozen rapidly in an alcohol-dry-ice bath, and stored in a dry-ice cabinet.

The $6 \mathrm{hr}$. soluble antigen production test. Dilutions of the virus preparation were inoculated by the intra-allantoic route into groups of at least three eggs, and $6 \mathrm{hr}$. later their chorio-allantoic membranes were harvested. Extracts were made and the mean total logarithmic soluble antigen (SA) units in the chorio-allantoic membrane corresponding to each dilution of seed were determined. Full details of this test and of the other techniques used in the present study are given in the preceding paper (Finter \& Beale, 1956).

$I D_{50}: H A$ ratio. This is the ratio between the titres of infective virus and of haemagglutinins. With the titration techniques described, standard allantoic fluid virus usually has an $\mathrm{ID}_{50}: \mathrm{HA}$ ratio of $10^{6.5}$, while incomplete virus preparations harvested after inoculation of large amounts of seed virus have lower values (von Magnus, 1951).

\section{EXPERIMENTAL}

In the first experiment to be reported, a study was made of the infectivity by the $6 \mathrm{hr}$. soluble antigen production test of chorio-allantoic membranes harvested at various times after inoculation of a large amount of seed virus. 
Six eggs were inoculated with about $10^{4} \mathrm{ID}_{50}$ of D.S.P. virus, and their allantoic fluids were harvested and pooled $19 \mathrm{hr}$. later. This pool of standard virus contained $10^{8 \cdot 9} \mathrm{ID}_{50}, 10^{2 \cdot 4} \mathrm{HA}$ units, and $10^{2 \cdot 0}$ soluble antigen (SA) units per ml. $0.5 \mathrm{ml}$. amounts were inoculated without dilution into a number of 13th-day eggs ('first undiluted passage'). At each hour for the first $9 \mathrm{hr}$. after inoculation, and at the 13th, 17th and 21 st $\mathrm{hr}$., batches of six eggs were harvested and their allantoic fluids and chorio-allantoic membranes pooled. The pools were titrated for infective virus, haemagglutinins and soluble antigen. The changes with time in the various virus activities in the allantoic fluid are shown in Fig. 1A, and in the chorioallantoic membrane in Fig. 1B. It will be seen that the results are of the type usual for a first undiluted passage of standard virus (Henle \& Henle, 1949; Hoyle, 1948, 1950; von Magnus, 1951). In the chorio-allantoic membranes harvested 1 and $2 \mathrm{hr}$. after inoculation of the seed no haemagglutinin or soluble antigen could be detected. At the $3 \mathrm{rd} \mathrm{hr}$. there were high titres of both, the total amount of soluble antigen being greater than that inoculated in the seed, but that of haemagglutinin slightly less. As measured by the $72 \mathrm{hr}$. haemagglutinin formation test, the infectivity of the membranes did not increase until the 4th $\mathrm{hr}$. In the allantoic fluid, haemagglutinin and soluble antigen titres increased from the 4th and 5 th $\mathrm{hr}$. respectively. The infectivity titre did not vary significantly during the $21 \mathrm{hr}$. period of the experiment, the level observed being presumably due to unabsorbed seed virus.

The chorio-allantoic membrane pools from this first undiluted passage were all tested by the $6 \mathrm{hr}$. soluble antigen production method. Each extract was tested both undiluted and diluted $1 / 4,0.5 \mathrm{ml}$. amounts being inoculated into groups of four 13th-day fertile eggs. In Fig. $1 \mathrm{C}$, the mean total amounts of soluble antigen formed in the chorio-allantoic membranes of these eggs $6 \mathrm{hr}$. after inoculation of the two dilutions of each extract have been plotted against the hour at which the membranes in that extract were themselves harvested in the first undiluted passage. It will be seen that the membranes harvested at the lst and $2 \mathrm{nd} \mathrm{hr}$. of the undiluted passage did not give rise to measurable amounts of soluble antigen in $6 \mathrm{hr}$. even when inoculated undiluted. With membranes harvested from the $3 \mathrm{rd} \mathrm{hr}$. onwards, increasing amounts of soluble antigen were formed on subinoculation. Thus the appearance of infectivity in the chorio-allantoic membranes, as judged by the $6 \mathrm{hr}$. soluble antigen production test, coincided with the appearance of detectable levels of haemagglutinins and soluble antigen, and preceded by $1 \mathrm{hr}$. any increase in their infectivity as measured by the conventional $72 \mathrm{hr}$. haemagglutinin formation test.

In Fig. 2, the mean total amounts of soluble antigen formed in the $6 \mathrm{hr}$. test by the two dilutions of each membrane extract have been plotted against the corresponding number of $\mathrm{ID}_{50}$ inoculated. The two values obtained with each extract are joined by a line which is marked at its upper end with the hour of harvest in the first undiluted passage of the membranes in that extract. For clarity, the values obtained with the 8 th $\mathrm{hr}$. membranes have been omitted from the figure. Results obtained with a high-titre standard allantoic fluid virus preparation have also been plotted in Fig. 2 for comparison. It will be seen that all these membrane 

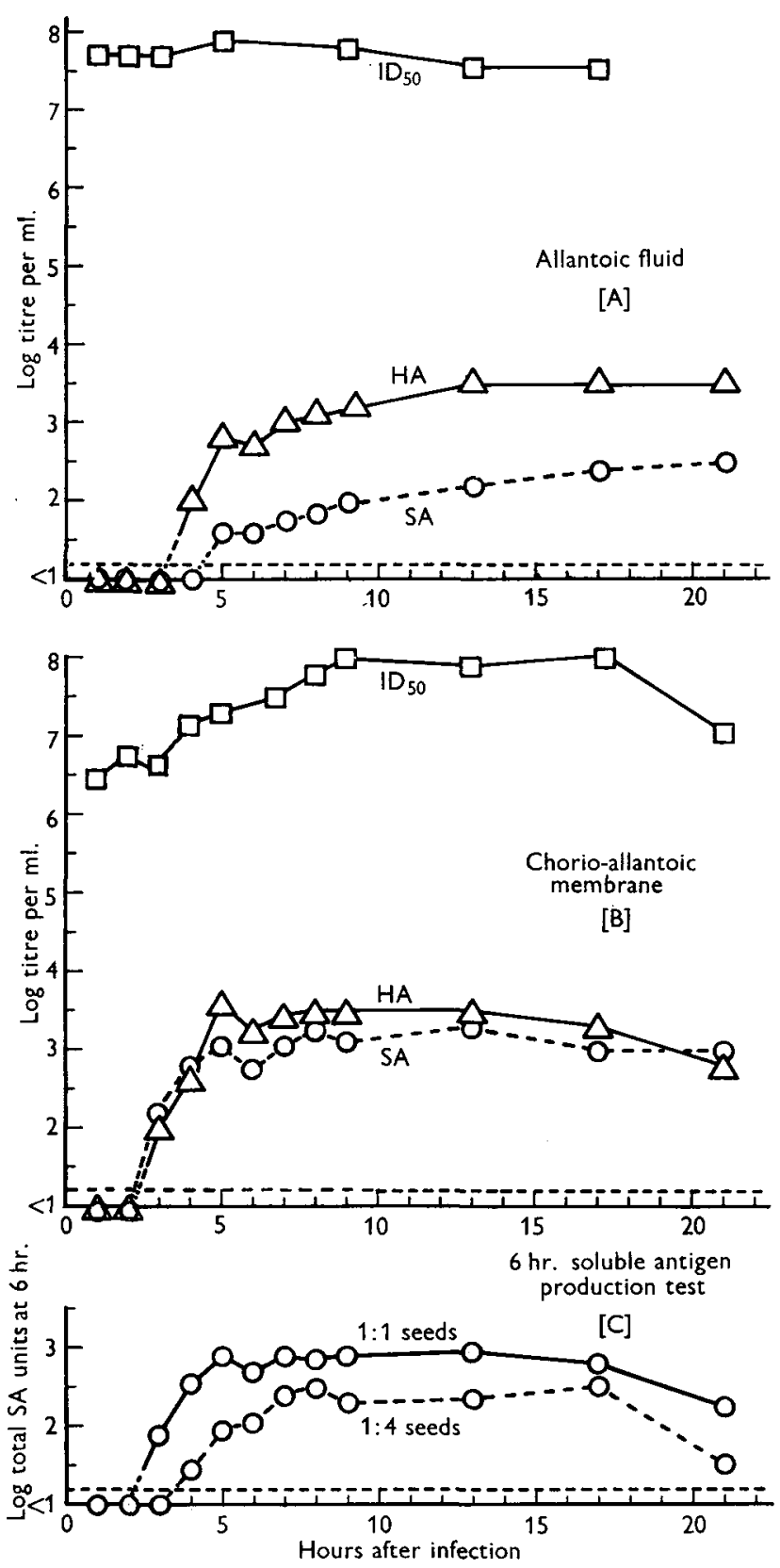

Fig. 1. Development of infectivity, haemagglutinins, and soluble complement-fixing antigen in the allantoic fluid (A), and chorio-allantoic membrane (B) after inoculation of eggs with $10^{8 \cdot 6} \mathrm{ID}_{50}$ of D.S.P. virus. $\mathrm{ID}_{50}=$ infectivity by conventional $72 \mathrm{hr}$. test. $\mathrm{HA}=$ haemagglutinin titre. $\mathrm{SA}=$ soluble antigen titre. (C) shows the results in the $6 \mathrm{hr}$. soluble antigen production test with $1 / 1$ and $1 / 4$ dilutions of the chorio-allantoic membranes of (B) plotted against the hour of their harvest. 
extracts produced more soluble antigen in $6 \mathrm{hr}$. than did an equivalent number of $\mathrm{ID}_{50}$ of standard virus. Thus, by this method chorio-allantoic membranes harvested from a first undiluted passage between 3 and at least $21 \mathrm{hr}$. after inoculation are all more infective than standard virus.

The logarithms of the $\mathrm{ID}_{50}: \mathrm{HA}$ ratios of the chorio-allantoic membrane extracts used as seeds are also shown in Fig. 2. It will be seen that for a given number of $\mathrm{ID}_{50}$ of seed virus inoculated, greater amounts of soluble antigen were produced by the extracts with lower $\mathrm{ID}_{50}$ : $\mathrm{HA}$ ratios (e.g. the 5th and 7 th hr. extracts) and

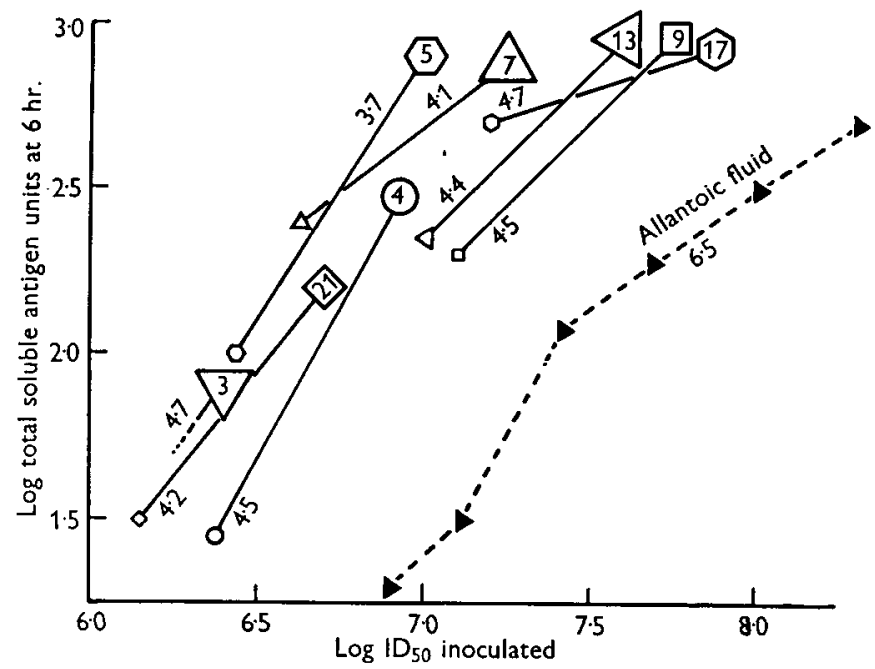

Fig. 2. Results in the $6 \mathrm{hr}$. soluble antigen production test with two dilutions of the chorioallantoic membranes shown in Fig. 1B, plotted against the $\mathrm{ID}_{50}$ inoculated. The figure inside the symbol gives the hour of harvest of the seed, and the figure along the line its logarithmic $\mathrm{ID}_{50}$ :HA ratio. Results with a standard allantoic fluid seed are shown for comparison (interrupted line).

smaller amounts by those with higher ratios (e.g. the 4th, 9 th and 13 th hr. extracts). Although the results do not fit exactly with the sequence of the seed $\mathrm{ID}_{50}: \mathrm{HA}$ ratios, it seemed that the ratio might be of importance in this connexion. Accordingly, an analysis was made of the results obtained in the $6 \mathrm{hr}$. soluble antigen production test with influenza virus preparations having a range of different $\mathrm{ID}_{50}:$ HA ratios.

Production of soluble antigen in $6 \mathrm{hr}$. with 'incomplete' influenza virus preparations

When eggs have been inoculated by the intra-allantoic route with large amounts of standard allantoic fluid virus (e.g. $\left.10^{9} \mathrm{ID}_{50}\right)$ and further incubated, their chorioallantoic membranes and allantoic fluid will contain virus with infectivity titres that are low, relative to the haemagglutinin titres. Such preparations with values for the $\mathrm{ID}_{50}: \mathrm{HA}$ ratio lower than that of standard virus (which with the present techniques is usually $10^{6.5}$ ) are said to contain 'incomplete' virus (von Magnus, 1951). The actual ratio will depend on factors such as the strain of influenza virus (Fazekas de St Groth \& Graham, 1954a), the number of $\mathrm{ID}_{50}$ of seed virus inocu- 
lated and its $\mathrm{ID}_{50}$ : HA ratio (Finter, Liu \& Henle, 1955), and on the time of harvest (cf. Fig. $1 \mathrm{~A}, \mathrm{~B}$ ). With the D.S.P. strain, virus preparations with $\mathrm{ID}_{50}: \mathrm{HA}$ ratios as low as $10^{3.5}$ for membrane extracts, and $10^{4.0}$ for allantoic fluids can be obtained in a single passage of undiluted allantoic fluid, and with even lower ratios by serial passages.

In a series of experiments a study was made of the infectivity by the $6 \mathrm{hr}$. soluble antigen production test of a number of influenza virus preparations with

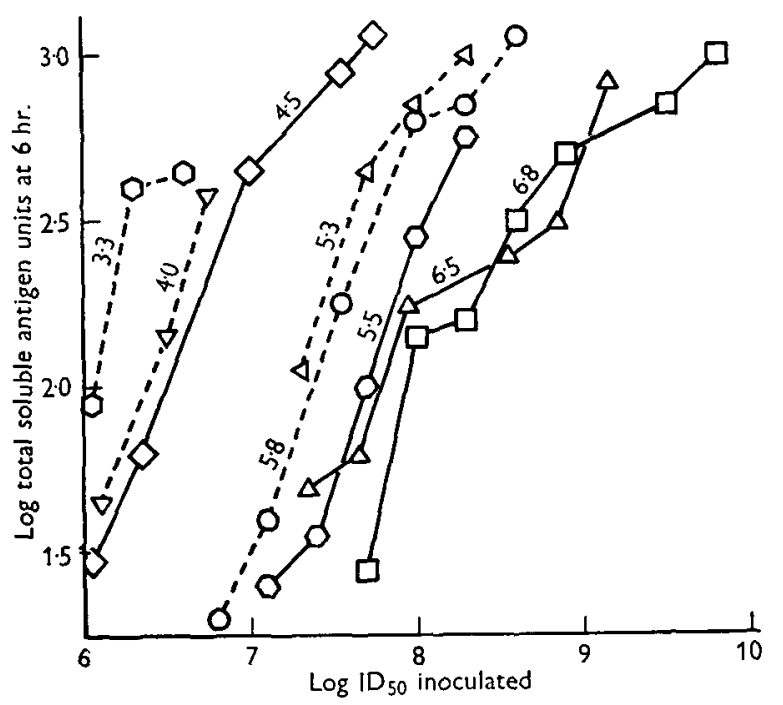

Fig. 3.

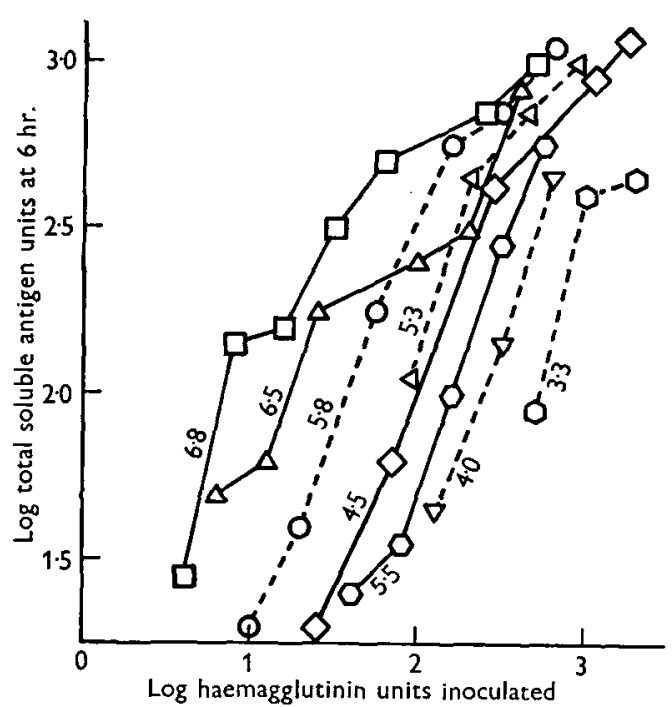

Fig. 4.

Figs. 3, 4. Results in the $6 \mathrm{hr}$. soluble antigen production test with eight different influenza virus preparations, plotted against the $\mathrm{ID}_{50}$ inoculated (Fig. 3) and the haemagglutinin (HA) units inoculated (Fig. 4). - - allantoic fluid seed; - . - -, chorio-allantoic membrane seed. The figure along each line gives the logarithmic $\mathrm{ID}_{50}: \mathrm{HA}$ ratio of that seed. 
different $\mathrm{ID}_{50}$ : HA ratios. For each experiment a single batch of eggs of the same age of incubation was used, though on the different occasions the actual age at the time of inoculation varied between 13 and $14 \frac{1}{2}$ days. In Fig. 3 the mean total amounts of soluble antigen per chorio-allantoic membrane formed in $6 \mathrm{hr}$. by dilutions of eight such preparations have been plotted against the corresponding numbers of $\mathrm{ID}_{50}$ of virus inoculated, values with allantoic fluid seeds being joined by continuous lines, and with membrane seeds by interrupted lines. The $\mathrm{ID}_{50}$ : $\mathrm{HA}$ ratio of each seed is also shown. It will be seen that the individual curves for soluble antigen production lie in a sequence which is in general the same as that of the seed $\mathrm{ID}_{50}: \mathrm{HA}$ ratios, though there are one or two discrepancies. For a given number of $\mathrm{ID}_{50}$ inoculated, larger amounts of soluble antigen were formed by seeds with lower $\mathrm{ID}_{50}$ :HA ratios, and smaller amounts by seeds with higher ratios, and this seemed to be so irrespective of whether the seeds were allantoic fluid or chorio-allantoic membrane virus preparations.

In Fig. 4 the amounts of soluble antigen formed in $6 \mathrm{hr}$. by the same eight seeds have been plotted against the numbers of haemagglutinin units inoculated. For a given number of haemagglutinin units inoculated, more soluble antigen was formed by seeds with higher $\mathrm{ID}_{50}: \mathrm{HA}$ ratios, and vice versa. Again the sequence of the curves for soluble antigen production by the individual seeds appears to be related to the $\mathrm{ID}_{50}: \mathrm{HA}$ ratios, but with one or two discrepancies.

Similar results were found with a considerable number of other allantoic fluid and chorio-allantoic membrane virus preparations tested, though to avoid confusion these have not been included in Figs. 3 and 4. With a few of these, the positions of the curves for soluble antigen production did not fit with the sequence of the seed $\mathrm{ID}_{50}$ :HA ratios. Such discrepancies might result from errors inherent in the various titrations involved, particularly in infectivity titrations by the conventional $72 \mathrm{hr}$. method (Knight, 1944). They might also be partly due to the use of eggs of slightly different ages in the different experiments, since the age at the time of inoculation has been found to influence the amount of soluble antigen formed in $6 \mathrm{hr}$. (Finter \& Beale, 1956). From the present data it seems probable that a chorio-allantoic membrane and an allantoic fluid preparation having the same $\mathrm{ID}_{50}$ : HA ratio would behave similarly in the $6 \mathrm{hr}$. test, though in view of the few discrepant results, it cannot be said with certainty that they would behave identically.

\section{DISCUSSION}

In previous reports (Beale, 1954; Finter \& Beale, 1956) a method has been described for comparing the infectivity of influenza virus preparations by inoculating dilutions into eggs, and measuring the amounts of soluble antigen in their chorio-allantoic membranes $6 \mathrm{hr}$. later (the $6 \mathrm{hr}$. soluble antigen production test). In the present paper it is shown that by this test extracts of chorio-allantoic membranes harvested between 3 and $21 \mathrm{hr}$. after inoculation of a large dose of seed are all more infective than the same amounts (in terms of $\mathrm{ID}_{50}$ ) of allantoic fluid virus grown from highly diluted seed (i.e. standard virus). The virus present in such membranes must therefore differ in some way from standard virus. 
Using eggs from which everything but the parietal portion of the chorioallantoic membrane had been removed ('de-embryonated eggs' (Bernkopf, 1950; Finter, Liu, Lieberman \& Henle, 1954)), it has been shown that virus is liberated from the chorio-allantoic membranes at nearly constant rates for more than $30 \mathrm{hr}$. after infection with the PR 8 strain of influenza A virus (Henle, Liu \& Finter, 1954). Essentially similar results, though with a somewhat shorter period of liberation, have been obtained with the D.S.P. strain (Finter, unpublished). Thus, once infected, chorio-allantoic membrane cells form virus for an extended period of time, during most of which they must contain virus precursors. Such precursors might be responsible for the high infectivity of chorio-allantoic membranes in the $6 \mathrm{hr}$. soluble antigen production test.

In support of this view the nature of the virus in a chorio-allantoic membrane $4 \frac{1}{2} \mathrm{hr}$. after inoculation of a large dose of standard virus may be considered. At this time there is much newly formed haemagglutinin and soluble antigen in the membrane, but the titre of infective virus as conventionally measured (i.e. by formation of haemagglutinins in $72 \mathrm{hr}$. on sub-inoculation) has increased but little over that found in the first $3 \mathrm{hr}$. after inoculation (ef. Fig. 1B). Thus the virus particles in the membrane at this time are predominantly endowed with haemagglutinating and complement-fixing properties, and have little or no infectivity in the sense of the $72 \mathrm{hr}$. test. It has been suggested (Hoyle, 1948, 1950; Henle \& Henle, 1949) that these particles represent a precursor stage in the formation of influenza virus. By the $6 \mathrm{hr}$. soluble antigen production test, extracts of such $4 \frac{1}{2} \mathrm{hr}$. membranes are much more infective per $\mathrm{ID}_{50}$ inoculated than standard virus. (Beale, 1954), and this again could be attributed to a content of precursors.

The view that these haemagglutinating particles in $4 \frac{1}{2} \mathrm{hr}$. chorio-allantoic membranes are precursors of normal extracellular virus is, however, open to the objection that they can only be detected after inoculation of very large doses of seed virus. Under these circumstances the virus in the chorio-allantoic membranes during subsequent incubation and also the virus liberated into the allantoic fluid is incomplete (von Magnus, 1951), i.e. has low titres of infectivity in relation to the haemagglutinin titres, and thus low values for the $\mathrm{ID}_{50}$ : $\mathrm{HA}$ ratio. It may, however, be pointed out that after inoculation of large amounts of seed, the $\mathrm{ID}_{50}: \mathrm{HA}$ ratios in the membranes are, in fact, lower between 4 and $7 \mathrm{hr}$. after inoculation than in the subsequent hours (cf. Fig. 1B, and also the growth curves of von Magnus (1951) and the data of Hoyle (1950)). Thus such haemagglutinating particles present in chorio-allantoic membranes between 4 and $7 \mathrm{hr}$. after infection may be considered as precursors, of even lower infectivity, of the incomplete virus found after further incubation in both the membranes and allantoic fluid.

The high infectivity by the $6 \mathrm{hr}$. soluble antigen production test of membranes harvested after inoculation of a large amount of seed might alternatively be attributed to their content of incomplete virus. Results obtained in the $6 \mathrm{hr}$. test with different preparations of influenza virus would seem to support this view. Allantoic fluids and chorio-allantoic membranes harvested after inoculation of undiluted standard virus and also of highly diluted seed were tested. The amounts of soluble antigen produced in $6 \mathrm{hr}$. by dilutions of these preparations were 
plotted against the number of $\mathrm{ID}_{50}$ inoculated at each dilution (Fig. 3), and also against the number of haemagglutinin units (Fig. 4). The results with the different preparations fell into a sequence which was in general the same as that of the $\mathrm{ID}_{50}: \mathrm{HA}$ ratios of the preparations, irrespective of whether these were allantoic fluids or chorio-allantoic membranes. Preparations with low $\mathrm{ID}_{50}$ : HA ratios, i.e. containing large amounts of incomplete virus, produced the largest amounts of soluble antigen per $\mathrm{ID}_{50}$ inoculated. For reasons which have been given, it cannot be said from the present data whether a membrane extract and an allantoic fluid having the same value for the $\mathrm{ID}_{50}: \mathrm{HA}$ ratio would behave identically in the soluble antigen production test, though this appears likely.

A content either of precursor virus or of incomplete virus might therefore account for the high infectivity of chorio-allantoic membranes in the soluble antigen production test. Experimental evidence presented and reviewed by Henle (1953) suggests that these may in fact be the same thing, incomplete virus in membranes representing an intermediary stage in virus reproduction. From the apparent similarity of behaviour in the soluble antigen test of allantoic fluids and membranes with the same $\mathrm{ID}_{50}^{\cdot}$ : $\mathrm{HA}$ ratio, it would seem possible that incomplete virus in allantoic fluid may also represent virus precursor forms. It has been suggested by Hoyle (personal communication) that, after inoculation of large amounts of virus, such particles with low $\mathrm{ID}_{50}: \mathrm{HA}$ ratios might be prematurely released into the allantoic fluid from chorio-allantoic cells whose cell membranes had been weakened by the enzymic activity of the correspondingly large amounts of unabsorbed seed virus. The artificial production of incomplete virus in eggs in which the chorio-allantoic membranes had been previously treated with periodate (Fazekas de St Groth \& Graham, 1954b) would seem to support this suggestion.

It will be clear from Fig. 4 that incomplete virus, whether from membranes or allantoic fluid, produces less soluble antigen in $6 \mathrm{hr}$. than the same number of haemagglutinin units of standard allantoic fluid virus. From direct counts under the electron microscope, Donald \& Isaacs (1954) have shown that the same number of particles of incomplete allantoic fluid virus and of standard virus comprise one haemagglutinin unit. It follows that the number of virus particles which must be inoculated to form a given amount of soluble antigen in $6 \mathrm{hr}$. is larger for allantoic fluid incomplete virus than for standard virus. It would seem likely that the same is true for chorio-allantoic membrane incomplete virus. Thus, whatever the average number of particles of standard virus which must infect the cells of the chorio-allantoic membrane to form a given amount of soluble antigen in $6 \mathrm{hr}$,, a larger number of particles of incomplete virus is needed. It has been shown by Henle \& Liu (1951) that after multiple infection of allantoic cells with influenza virus which had been partially inactivated by ultra-violet irradiation, production of both haemagglutinins and of infective virus proceeded at rates corresponding to infection with more than ten times the number of $\mathrm{ID}_{50}$ actually found in the irradiated seed (multiplicity reactivation). The synergistic effect, in terms of soluble antigen production, of multiple infection with incomplete virus particles both of allantoic cells, as noted in the present study, and of chorionic cells, as noted by Isaacs \& Fulton (1953) would seem to be an analogous phenomenon. It 
may also be suggested that the low infectivity of incomplete virus preparations in the conventional test may be in part due to a similar need for multiple infection of at least one cell, with subsequent reactivation leading to a propagated infection of all the cells. If this is so, the $\mathrm{ID}_{50}: \mathrm{HA}$ ratio of an incomplete virus preparation would not represent merely its content on the one hand of 'complete' virus, and on the other of entirely non-infective haemagglutinating particles.

\section{SUMMARY}

1. After inoculation of eggs with a large dose $\left(10^{8 \cdot 6} \mathrm{ID}_{50}\right)$ of influenza virus, chorio-allantoic membranes harvested from the $3 \mathrm{rd}$ to at least the $21 \mathrm{st} \mathrm{hr}$. (but not at the lst or $2 \mathrm{nd} \mathrm{hr}$.) gave rise to large amounts of soluble antigen in $6 \mathrm{hr}$. in the chorio-allantoic membranes of sub-inoculated eggs $(6 \mathrm{hr}$. soluble antigen production test). These amounts were larger than resulted from inoculation of equivalent numbers of $\mathrm{ID}_{50}$ of standard allantoic fluid virus. By the conventional $72 \mathrm{hr}$. test, the infectivity of the chorio-allantoic membranes increased $1 \mathrm{hr}$. later, at the 4th hr. after inoculation.

2. Allantoic fluids and chorio-allantoic membranes harvested from passages of very large and of small amounts of influenza virus were tested by $6 \mathrm{hr}$. soluble antigen production. The relative amounts of soluble antigen formed by different seeds appeared to be determined by their $\mathrm{ID}_{50}: \mathrm{HA}$ ratios, irrespective of whether they were allantoic fluid or chorio-allantoic membrane preparations. Larger amounts of soluble antigen were formed in $6 \mathrm{hr}$. per $\mathrm{ID}_{50}$ inoculated by preparations having lower $\mathrm{ID}_{50}$ : $\mathrm{HA}$ ratios, i.e. containing larger amounts of 'incomplete' virus, and vice versa.

3. It is suggested that high infectivity in the $6 \mathrm{hr}$. soluble antigen test per $\mathrm{ID}_{50}$ inoculated is due to a content of 'incomplete' virus, or of virus precursors : possibly these are in fact the same.

4. More particles of an incomplete virus preparation than of standard allantoic fluid virus must be inoculated to produce a given amount of soluble antigen in $6 \mathrm{hr}$. It is suggested that a process resembling multiplicity reactivation must occur in cells infected with more than one particle of 'incomplete' virus.

We are grateful to Dr L. Hoyle for his helpful and critical interest in the work reported in this and in the preceding paper, and also to $\mathrm{Mr} \mathrm{J}$. Collins for much valuable technical assistance.

\section{REFERENCES}

Beale, A. J. (1954). A comparison of the soluble antigen production by tissues infected with preparations of extracellular and intracellular influenza virus. J. Hyg., Camb., 52, 225.

BERnKoPF, H. (1950). Study of infectivity and hemagglutination of influenza virus in deembryonated eggs. J. Immunol. 65, 571 .

Donald, H. B. \& IsaAcs, A. (1954). Counts of influenza virus particles. J. gen. Microbiol. $10,457$.

Fazekas de St Groth, S. \& Graham, D. M. (1954a). The production of incomplete virus particles among influenza strains : experiments in eggs. Brit. J. exp. Path. 35, 60. 
Fazeras de St Groth, S. \& Graham, D. M. (1954b). Artificial production of incomplete influenza virus. Nature, Lond., 173, 637.

Finter, N. B. \& Beale, A. J. (1956). The 6-hour soluble antigen production test for comparing the infectivity of influenza, virus preparations. J. Hyg., Camb., 53, 58.

Finter, N. B., Liv, O. C., Lieberman, M. \& Hente, W. (1954). Studies on host-virus interactions in the chick embryo-influenza virus system. 8. An experimental analysis of various deembryonation technics. J. exp. Med. 100, 33.

Finter, N. B., Lro, O. C. \& Hente, W. (1955). Studies on host-virus interactions in the chick embryo-influenza virus system. 10. An experimental analysis of the von Magnus phenomenon. J. exp. Med. 101, 461.

Henle, W. (1953). Developmental cycles in animal viruses. Cold Spr. Harb. Symp. quant. Biol. 18, 35.

Hence, W. \& Henle, G. (1949). Studies on host-virus interactions in the chick embryoinfluenza virus system. 3. Development of infectivity, hemagglutination, and complement fixation activities during the first infectious cycle. J. exp. Med. 90, 23.

Hente, W. \& Lru, O. C. (1951). Studies on host-virus interactions in the chick embryoinfluenza virus system. 6. Evidence for multiplicity reactivation of inactivated virus. J. exp. Med. 94, 305.

Henle, W., Liv, O. C. \& Finter, N. B. (1954). Studies on host-virus interactions in the chick embryo-influenza virus system. 9. The period of liberation of virus from infected cells. J. exp. Med. 100, 53.

HoxLE, L. (1948). The growth cycle of influenza virus A. A study of the relations between virus, soluble antigen, and host cell in fertile eggs inoculated with influenza virus. Brit. J. exp. Path. 29, 390.

Hoyce, L. (1950). The multiplication of influenza viruses in the fertile egg. J. Hyg., Camb., 48, 277.

IsaAcs, A. \& Fulton, F. (1953). Interference in the chick chorion. J. gen. Microbiol. 9, 132.

KNIGHT, C. A. (1944). Titration of influenza virus in chick embryos. J. exp. Med. 79, 487.

Muller, G. L. \& Standey, W. M. (1944). Quantitative aspects of the red cell agglutination test for influenza virus. J. exp. Med. 79, 185.

REED, L. J. \& MUENCH, H. (1938). A simple method of estimating $50 \%$ end-points. Amer. J. Hyg. 27, 493.

SALK, J. E. (1944). A simplified procedure for titrating haemagglutinating capacity of influenza virus and the corresponding antibody. J. Immunol. 49, 87.

von Magnus, P. (1951). Propagation of the PR 8 strain of influenza virus in chick embryos. 2. The formation of 'incomplete' virus following inoculation of large doses of seed virus. Acta path. microbiol. scand. 28, 278.

(MS. received for publication 25. vII. 55) 